OPEN ACCESS

Edited by:

T. John Wu,

Uniformed Services University of the Health Sciences, United States

Reviewed by:

Andres M. Rubiano

El Bosque University, Colombia

Courtney L. Robertson,

Johns Hopkins University,

United States

${ }^{*}$ Correspondence:

Zachary M. Weil

zachary.weil@hsc.wvu.edu

Specialty section:

This article was submitted to

Neurotrauma

a section of the journal

Frontiers in Neurology

Received: 29 March 2020

Accepted: 02 September 2020

Published: 19 October 2020

Citation:

Oliverio R, Karelina K and Weil ZM (2020) Sex, Drugs, and TBI: The Role of Sex in Substance Abuse Related to

Traumatic Brain Injuries.

Front. Neurol. 11:546775.

doi: 10.3389/fneur.2020.546775

\section{Sex, Drugs, and TBI: The Role of Sex in Substance Abuse Related to Traumatic Brain Injuries}

\author{
Robin Oliverio, Kate Karelina and Zachary M. Weil ${ }^{\star}$
}

Department of Neuroscience and Rockefeller Neuroscience Institute, West Virginia University School of Medicine, Morgantown, WV, United States

Traumatic brain injuries (TBI) are a significant public health problem costing billions of dollars in healthcare costs and lost productivity while simultaneously reducing the quality of life for both patients and caregivers. Substance abuse is closely interconnected with TBI, as intoxicated individuals are at a greater risk of suffering brain injuries, and TBI may serve as a risk factor for the subsequent development of substance use disorders. There are also prominent sex differences in the etiology, epidemiology, and consequences of TBI. For instance, men are more likely to be injured on sporting fields or in auto accidents, while women are disproportionately likely to suffer TBI associated with intimate partner violence. Moreover, while men are much more likely to suffer TBI during late adolescence-young adulthood, sex differences in the incidence of TBI are much less prominent during other developmental epochs. Further, there are prominent sex differences in substance abuse biology; for example, while more men meet diagnostic criteria for substance abuse disorders, women tend to advance from casual use to addiction more quickly. In this paper, we will discuss the emerging clinical and preclinical evidence that these sex differences in TBI and substance abuse interact and may be prominent determinates of long-term outcomes.

Keywords: traumatic brain injury, substance abuse, sex differences, epidemiology, adolescent brain injury

\section{INTRODUCTION}

Sex differences are prominent components of the biology of substance abuse. Men more commonly partake in substance use and are more likely to develop dependence than women (1-4), although compared to men, women tend to more rapidly progress from beginning use, to dependence, to treatment-seeking of many substances including alcohol, marijuana, and cocaine $(2,5,6)$. This difference is commonly observed in alcohol use disorder (AUD), where women often begin drinking at a later age and progress through the stages of abuse at a faster rate than men $(6,7)$. However, this concept has become contentious, with recent studies suggesting that this phenomenon is not the case in the general population and that sex differences in AUD have begun to decrease $(4,8)$.

Sex differences exist within the withdrawal stage of substance abuse as well. Compared to men, women have shorter periods of cessation from smoking and report greater difficulties in quitting $(2,9,10)$. Hogle and Curtin (11) found that women showed more of a negative affective response to a conditioned fear stimulus during nicotine withdrawal. Additionally, women attempting to quit cocaine have shorter periods of abstinence than men and report more intense cravings in response to stimuli related to cocaine use during withdrawal $(12,13)$. 
Here, we will examine the emerging data on sex differences in substance abuse among traumatic brain injury (TBI) survivors. TBI places a significant burden on health and the economy in the United States, causing $\sim 1.7$ million individuals to seek treatment and costing $\$ 60$ billion in combined indirect and direct costs annually $(14,15)$. Further, TBI often results in long-term disability, leading to an increased burden on relatives and substantial decreases in lifetime productivity $(16,17)$. Sex differences in TBI incidence are well-documented; however, given the intense media attention on the role of contact sportsrelated head injuries, and the general focus on men across biomedical research, it is not surprising that disproportionate research attention has been focused on men. This approach is very likely to undermine progress in prevention and treatment of TBI and related outcomes in both sexes. Putting aside for a moment the possibility that TBI pathophysiology may be different across sexes, it is absolutely clear that there are prominent sex differences in TBI incidence and etiology. For instance, men are more commonly treated than women for TBI (14), although this sex difference in the incidence of TBI may well-underestimate the true scope of injuries to women, as men tend to suffer more severe injuries and are consequently more likely to seek (or require) medical treatment. Critically, this prominent sex difference in TBI incidence narrows considerably if stratified across ages. The largest male bias in TBI incidence occurs between adolescence and young adulthood and is largely absent in other developmental epochs (most prominently early childhood and retirement age). Moreover, the etiology of injuries also differs prominently. For example, men are much more likely to suffer a TBI in the workplace, or on the sporting field, while women are disproportionately injured by intimate partner violence (18-20). Epidemiological results vary with respect to sex differences in outcomes following TBI, although some studies suggest that women fare worse in a majority of measurements, particularly for mild injuries, whereas men appear to exhibit worse outcomes after more severe injuries (21-25). Women experience a longer duration of posttraumatic amnesia and hospitalization and have a greater likelihood of requiring surgical intervention $(21,24)$. Female TBI patients are also more likely to be admitted to the intensive care unit (ICU) and remain in the ICU longer than male patients (26). Additionally, among mild TBI patients, women are more likely to experience longterm ( 3 years postinjury) postconcussion symptoms than men, including headache, dizziness, nausea, noise sensitivity, fatigue, sleep disturbance, and spinal pain (27). Adult women who sustained a pediatric TBI more commonly report symptoms consistent with major depressive disorder and anxiety disorders compared to adult men who report more externalizing behavior such as aggression and substance abuse (28). Moreover, even among the adolescent-young adult cohort, the disparity between injury incidences among the sexes might be decreasing due to an increasing prevalence of female involvement in sports and military combat (29-31).

These sex differences in incidence, severity, and etiology are critically important determinants of the relationship between TBI and substance abuse (Figure 1). TBI is bidirectionally linked to substance abuse. First, intoxication at the time of injury is a very common feature of TBI patients $(32,33)$, and driving while intoxicated has been noted to increase the risk of TBI (34, 35). The impact of intoxication while driving on TBI outcomes varies considerably, with some studies indicating that high blood alcohol level during a motor vehicle accident increases TBI severity $(36,37)$, some providing evidence of decreased TBI severity (38-40), and still others showing no significant difference in TBI outcome $(41,42)$. Of note, the prevalence of intoxication at the time of injury can vary significantly across sex. For instance, among TBI patients treated at one of two trauma centers in the Netherlands, $33 \%$ of individuals were intoxicated at the time of their injury. This subset of patients was both younger (38 years of age) and more likely to be male (78\%) than the patients who were not intoxicated at the time of their injuries (40 years of age and $60 \%$ male) (43). The larger number of men intoxicated at the time of their injury is not entirely surprising given that younger men are more likely to engage in risky or violent behavior and that this is exacerbated by substance use $(44,45)$.

One consequence of the large number of individuals intoxicated at the time of their injuries is that the TBI patient population consists disproportionately of individuals with a history of substance misuse (46). This is important because a history of substance abuse, as well as continued use after injury, can predict worsened outcomes, reduced recovery, and even increased likelihood of subsequent TBIs $(38,47)$. For example, a history of substance abuse increases the probability of a more severe injury from motor vehicle accidents or falls from great heights (39), as well as a greater probability of mass lesions and mortality and poorer outcomes upon release from the hospital (38). Additionally, a history of alcohol abuse prior to brain injury is associated with greater neuropsychological deficits and mood disorders following a TBI $(47,48)$. In general, among individuals with a history of alcohol abuse, drinking behavior tends to decline acutely after injury, particularly with more severe injuries (49). However, some percentage of individuals (more commonly men) gradually return to high levels of drinking after their injuries $(50,51)$.

Third, experiencing a TBI, especially prior to or during adolescence, is associated with a greater risk of developing a substance use disorder later (52-54). This relationship has been difficult to establish epidemiologically; however, there is mounting evidence that early TBI can serve as a risk factor for the development of substance abuse issues [reviewed in (55)]. There is much less known as to whether these relationships are similar across sexes, and the potential roles are often overshadowed by the higher baseline levels of both TBI and substance abuse among men (56). One interesting finding that we recently reported emerged from an analysis of individuals from Ohio self-reporting their history of TBI and current drinking patterns. Individuals with a history of TBI before age 20 were more likely to binge drink as adults, and regardless of injury history, men reported higher incidence of binge drinking than did women. However, women injured during adolescence were more likely to drink than those injured either early or later in their lives, an effect that was not apparent in men (57). These data indicate 


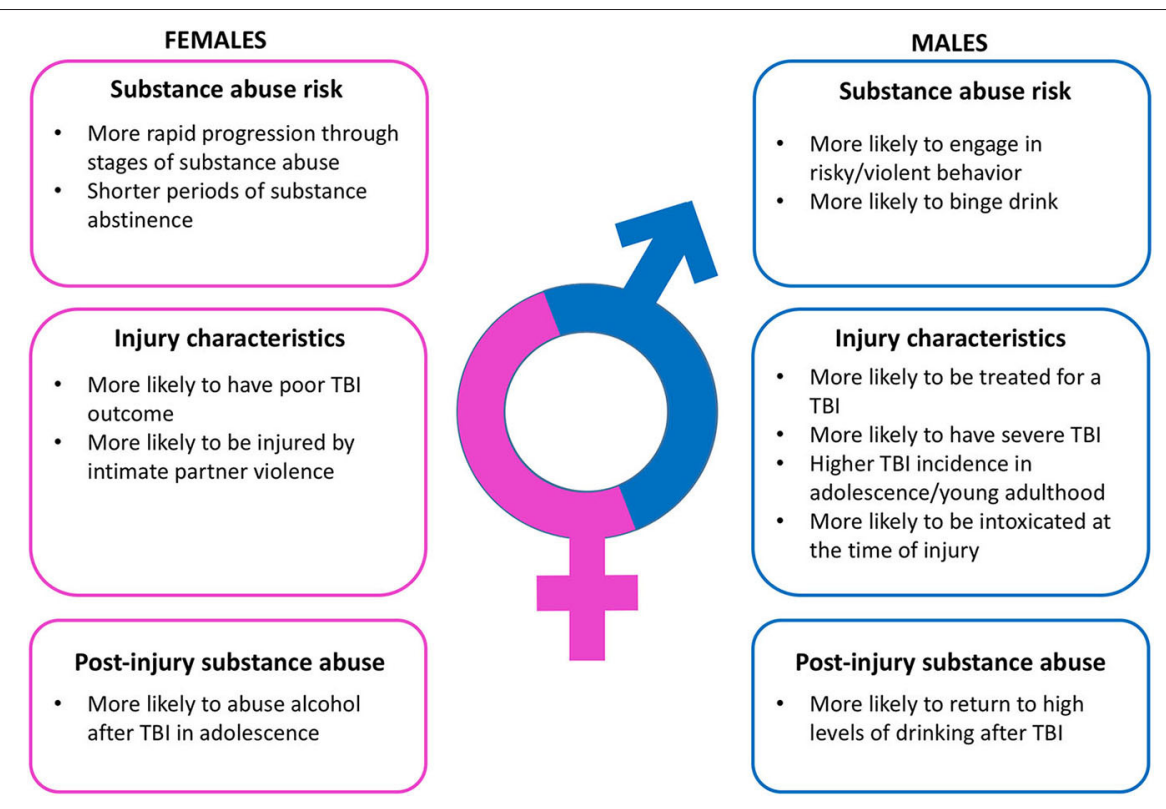

FIGURE 1 | Summary of relevant sex differences in substance abuse risk, traumatic brain injury characteristics, and post-injury substance abuse.

that sex differences in the patterns and types of injuries could have major implications for the relationship between TBI and substance abuse.

Given that there are clear sex differences in substance abuse and TBI, it follows that sex differences present differential risks for the development of substance abuse disorders following TBI. However, this remains largely unstudied. Epidemiological studies in veterans who experienced a TBI show that men are more likely than women to develop an alcohol use disorder (AUD) and non-alcohol substance use disorder (SUD) as well as generally exhibit alcohol misuse $(58,59)$. The overall prevalence of alcohol misuse after TBI is $6.8-16.2 \%$ in women compared with $20.3-$ $27 \%$ in men. Further, men who sustained a mild TBI prior to adulthood are more likely to report experiencing substance abuse and dependence (28). However, overall sex differences in substance abuse following TBI remain poorly understood and severely understudied. Much more investigation is needed in this area to elucidate this relationship.

Preclinical studies into the relationship between TBI and the development of substance abuse issues have reported that TBI can facilitate drug-related behavior. Specifically, TBI has been shown to enhance self-administration or conditioned place preference acquisition of alcohol $(60,61)$, cocaine (62, 63), and opiates (64) although not all studies have reported facilitating effects of injury on drug-related behavior [e.g., (65)]. Notably, virtually all these studies were conducted in male rodents. One study that did systematically examine potential sex differences reported that female, but not male mice, injured at postnatal day 21 exhibited enhanced alcohol selfadministration (61). This appeared to be due to differences in the rewarding properties of alcohol, as immediate early gene activation was altered in the reward pathway following alcohol injection and conditioned place preference responses to alcohol were apparent in injured female mice only. Moreover, injury in adulthood did not alter alcohol-related behavior in either sex. Thus, much like in the clinical picture, sex and age at injury are critical determinates of substance-abuse-related phenomena $(57,66)$.

\section{CONCLUSION}

Our understanding of the patterns and consequences of TBI are rapidly evolving, and it is becoming increasingly clear that men and women vary significantly in the incidence and consequence of these injuries. Moreover, TBI-related substance abuse is a major issue that can significantly alter long-term outcomes and the risk for repeated injuries. We know that there are prominent sex differences in substance abuse more generally, and thus, it is highly likely that sex will be a critical determinant of the relationship between TBI and substance abuse, although much more clinical and preclinical work is necessary.

\section{AUTHOR CONTRIBUTIONS}

RO, KK, and ZW wrote and edited the manuscript. All authors contributed to the article and approved the submitted version.

\section{FUNDING}

Support for the preparation of this article was provided by the National Institute on Alcohol Abuse and Alcoholism under award number R21AA026356. 


\section{REFERENCES}

1. Wilsnack RW, Vogeltanz ND, Wilsnack SC, Harris TR, Ahlstrom S, Bondy S, et al. Gender differences in alcohol consumption and adverse drinking consequences: cross-cultural patterns. Addiction. (2000) 95:251-65. doi: 10.1046/j.1360-0443.2000.95225112.x

2. Becker JB, Hu M. Sex differences in drug abuse. Front Neuroendocrinol. (2008) 29:36-47. doi: 10.1016/j.yfrne.2007.07.003

3. Kuhn C. Emergence of sex differences in the development of substance use and abuse during adolescence. Pharmacol Therapeut. (2015) 153:55-78. doi: 10.1016/j.pharmthera.2015.06.003

4. Delker E, Brown Q, Hasin DS. Alcohol consumption in demographic subpopulations an epidemiologic overview. Alcohol Res Curr Rev. (2016) 38:7-15.

5. Haas AL, Peters RH. Development of substance abuse problems among druginvolved offenders-evidence for the telescoping effect. J Substance Abuse. (2000) 12:241-53. doi: 10.1016/S0899-3289(00)00053-5

6. Mann K, Ackermann K, Croissant B, Mundle G, Nakovics H, Diehl A. Neuroimaging of gender differences in alcohol dependence: are women more vulnerable? Alcohol Clin Exp Res. (2005) 29:896-901. doi: 10.1097/01.ALC.0000164376.69978.6B

7. Brady KT, Randall CL. Gender differences in substance use disorders. Psychiatr Clin North Am. (1999) 22:241. doi: 10.1016/S0193-953X(05)70074-5

8. Keyes KM, Grant BF, Hasin DS. Evidence for a closing gender gap in alcohol use, abuse, and dependence in the United States population. Drug Alcohol Dependence. (2008) 93:21-9. doi: 10.1016/j.drugalcdep.2007.08.017

9. Wetter DW, Kenford SL, Smith SS, Fiore MC, Jorenby DE, Baker TB. Gender differences in smoking cessation. J Consult Clin Psychol. (1999) 67:555-62. doi: 10.1037/0022-006X.67.4.555

10. Scharf D, Shiffman S. Are there gender differences in smoking cessation, with and without bupropion? Pooled- and meta-analyses of clinical trials of Bupropion SR. Addiction. (2004) 99:1462-9. doi: 10.1111/j.1360-0443.2004.00845.x

11. Hogle JM, Curtin JJ. Sex differences in negative affective response during nicotine withdrawal. Psychophysiology. (2006) 43:344-56. doi: 10.1111/j.1469-8986.2006.00406.x

12. Griffin ML, Weiss RD, Mirin SM, Lange U. A comparison of male and female cocaine abusers. Archiv General Psychiatry. (1989) 46:122-6. doi: 10.1001/archpsyc.1989.01810020024005

13. Robbins SJ, Ehrman RN, Childress AR, O'brien CP. Comparing levels of cocaine cue reactivity in male and female outpatients. Drug Alcohol Depend. (1999) 53:223-30. doi: 10.1016/S0376-8716(98)00135-5

14. Faul MD, Xu L, Wald MM, Coronado VG. Traumatic Brain Injury in the United States: Emergency Department Visits, Hospitalizations, and Deaths, 2002-2006. Atlanta, GA (2010). doi: 10.15620/cdc.5571

15. Coronado VG, Mcguire LC, Sarmiento K, Bell J, Lionbarger MR, Jones CD, et al. Trends in Traumatic Brain Injury in the U.S. and the public health response: 1995-2009. J Safety Res. (2012) 43:299-307. doi: 10.1016/j.jsr.2012.08.011

16. Finkelstein E, Corso PS, Miller TR. The Incidence and Economic Burden of Injuries in the United States. Oxford: Oxford University Press (2006). doi: 10.1093/acprof:oso/9780195179484.001.0001

17. Selassie AW, Zaloshnja E, Langlois JA, Miller T, Jones P, Steiner C. Incidence of long-term disability following traumatic brain injury hospitalization, United States, 2003. J Head Trauma Rehabil. (2008) 23:12331. doi: 10.1097/01.HTR.0000314531.30401.39

18. Heyer NJ, Franklin GM. Work-related traumatic brain injury in WashingtonState, 1988 through 1990. Am J Public Health. (1994) 84:1106-9. doi: 10.2105/AJPH.84.7.1106

19. St Ivany A, Schminkey D. Intimate partner violence and traumatic brain injury state of the science and next steps. Family Commun Health. (2016) 39:129-37. doi: 10.1097/FCH.0000000000000094

20. Mollayeva T, Mollayeva S, Colantonio A. Traumatic brain injury: sex, gender and intersecting vulnerabilities. Nat Rev Neurol. (2018) 14:712-23. doi: 10.1038/s41582-018-0091-y

21. Farace E, Alves WM. Do women fare worse? A metaanalysis of gender differences in outcome after traumatic brain injury. Neurosurg Focus. (2000) 8:e6. doi: 10.3171/foc.2000.8.1.152
22. Broshek DK, Kaushik T, Freeman JR, Erlanger D, Webbe F, Barth JT. Sex differences in outcome following sports-related concussion. Journal of Neurosurgery. (2005) 102:856-63. doi: 10.3171/jns.2005.102.5.0856

23. Dick RW. Is there a gender difference in concussion incidence and outcomes? Br J Sports Med. (2009) 43(Suppl.1):i46-50. doi: 10.1136/bjsm.2009.058172

24. Munivenkatappa A, Agrawal A, Shukla DP, Kumaraswamy D, Devi BI. Traumatic brain injury: does gender influence outcomes? Int J Crit Illn Inj Sci. (2016) 6:70-3. doi: 10.4103/2229-5151.183024

25. Gupte R, Brooks W, Vukas R, Pierce J, Harris J. Sex differences in traumatic brain injury: what we know and what we should know. J Neurotrauma. (2019) 36:3063-91. doi: 10.1089/neu.2018.6171

26. Ley EJ, Short SS, Liou DZ, Singer MB, Mirocha J, Melo N, et al. Gender impacts mortality after traumatic brain injury in teenagers. J Trauma Acute Care Surg. (2013) 75:682-6. doi: 10.1097/TA.0b013e31829d024f

27. Styrke J, Sojka P, Bjornstig U, Bylund PO, Stalnacke BM. Sex-differences in symptoms, disability, and life satisfaction three years after mild traumatic brain injury: a population-based cohort study. J Rehabil Med. (2013) 45:74957. doi: 10.2340/16501977-1215

28. Scott C, Mckinlay A, Mclellan T, Britt E, Grace R, Macfarlane M. A comparison of adult outcomes for males compared to females following pediatric traumatic brain injury. Neuropsychology. (2015) 29:501-8. doi: $10.1037 /$ neu0000074

29. Knowles SB. Is there an injury epidemic in girls' sports? Br J Sports Med. (2010) 44:38-44. doi: 10.1136/bjsm.2009.065763

30. Amara J, Iverson KM, Krengel M, Pogoda TK, Hendricks A. Anticipating the traumatic brain injury-related health care needs of women veterans after the Department of Defense Change in Combat Assignment Policy. Womens Health Issues. (2014) 24:E171-6. doi: 10.1016/j.whi.2013.12.004

31. Mcglade E, Rogowska J, Yurgelun-Todd D. Sex differences in orbitofrontal connectivity in male and female veterans with TBI. Brain Imaging Behav. (2015) 9:535-49. doi: 10.1007/s11682-015-9379-3

32. Kolakowsky-Hayner SA, Gourley EV 3rd, Kreutzer JS, Marwitz JH, Cifu DX, Mckinley WO. Pre-injury substance abuse among persons with brain injury and persons with spinal cord injury. Brain Inj. (1999) 13:571-81. doi: 10.1080/026990599121313

33. Bombardier $\mathrm{CH}$, Rimmele CT, Zintel H. The magnitude and correlates of alcohol and drug use before traumatic brain injury. Archiv Phys Med Rehabil. (2002) 83:1765-73. doi: 10.1053/apmr.2002.36085

34. Stocchetti N. Traumatic brain injury: problems and opportunities. Lancet Neurol. (2014) 13:14-6. doi: 10.1016/S1474-4422(13)70280-1

35. Seesen M, Siviroj P, Sapbamrer R, Morarit S. High blood alcohol concentration associated with traumatic brain injury among traffic injury patients during New Year festivals in Thailand. Traffic Injury Prev. (2019) 20:115-21. doi: 10.1080/15389588.2018.1547379

36. Cunningham RM, Maio RF, Hill EM, Zink BJ. The effects of alcohol on head injury in the motor vehicle crash victim. Alcohol Alcohol. (2002) 37:236-40. doi: 10.1093/alcalc/37.3.236

37. Tien HC, Tremblay LN, Rizoli SB, Gelberg J, Chughtai T, Tikuisis $\mathrm{P}$, et al. Association between alcohol and mortality in patients with severe traumatic head injury. Arch Surg. (2006) 141:1185-91. doi: 10.1001/archsurg.141.12.1185

38. Corrigan JD. Substance abuse as a mediating factor in outcome from traumatic brain injury. Archiv Phys Med Rehabil. (1995) 76:302-9. doi: 10.1016/S0003-9993(95)80654-7

39. Andelic N, Jerstad T, Sigurdardottir S, Schanke AK, Sandvik L, Roe C. Effects of acute substance use and pre-injury substance abuse on traumatic brain injury severity in adults admitted to a trauma centre. J Trauma Manag Outcomes. (2010) 4:6. doi: 10.1186/1752-2897-4-6

40. Opreanu RC, Kuhn D, Basson MD. Influence of alcohol on mortality in traumatic brain injury. J Am Coll Surg. (2010) 210:997-1007. doi: 10.1016/j.jamcollsurg.2010.01.036

41. Alexander S, Kerr ME, Yonas H, Marion DW. The effects of admission alcohol level on cerebral blood flow and outcomes after severe traumatic brain injury. J Neurotrauma. (2004) 21:575-83. doi: 10.1089/0897715047741 29900

42. Shandro JR, Rivara FP, Wang J, Jurkovich GJ, Nathens AB, Mackenzie EJ. Alcohol and risk of mortality in patients with traumatic brain injury. $J$ Trauma. (2009) 66:1584-90. doi: 10.1097/TA.0b013e318182af96 
43. Scheenen ME, De Koning ME, Van Der Horn HJ, Roks G, Yilmaz T, Van Der Naalt J, et al. Acute alcohol intoxication in patients with mild traumatic brain injury: characteristics, recovery, and outcome. J Neurotrauma. (2016) 33:339-45. doi: 10.1089/neu.2015.3926

44. Rogers RG, Everett BG, Saint Onge JM, Krueger PM. Social, behavioral, and biological factors, and sex differences in mortality. Demography. (2010) 47:555-78. doi: 10.1353/dem.0.0119

45. Wilsnack RW, Wilsnack SC, Gmel G, Kantor LW. Gender differences in binge drinking prevalence, predictors, and consequences. Alcohol Res Curr Rev. (2018) 39:57-76.

46. Corrigan JD, Bogner J, Mellick D, Bushnik T, Dams-O'connor K, Hammond FM, et al. Prior history of traumatic brain injury among persons in the Traumatic Brain Injury Model Systems National Database. Arch Phys Med Rehabil. (2013) 94:1940-50. doi: 10.1016/j.apmr.2013. 05.018

47. Jorge RE, Starkstein SE, Arndt S, Moser D, Crespo-Facorro B, Robinson RG. Alcohol misuse and mood disorders following traumatic brain injury. Arch Gen Psychiatry. (2005) 62:742-9. doi: 10.1001/archpsyc. 62.7.742

48. Wilde EA, Bigler ED, Gandhi PV, Lowry CM, Blatter DD, Brooks J, et al. Alcohol abuse and traumatic brain injury: quantitative magnetic resonance imaging and neuropsychological outcome. J Neurotrauma. (2004) 21:137-47. doi: $10.1089 / 089771504322778604$

49. Bombardier CH, Temkin NR, Machamer J, Dikmen SS. The natural history of drinking and alcohol-related problems after traumatic brain injury. Arch Phys Med Rehabil. (2003) 84:185-91. doi: 10.1053/apmr.2003.50002

50. Horner MD, Ferguson PL, Selassie AW, Labbate LA, Kniele K, Corrigan JD. Patterns of alcohol use 1 year after traumatic brain injury: a populationbased, epidemiological study. J Int Neuropsychol Soc. (2005) 11:322-30. doi: 10.1017/S135561770505037X

51. Pagulayan KF, Temkin NR, Machamer JE, Dikmen SS. Patterns of alcohol use after traumatic brain injury. J Neurotrauma. (2016) 33:1390-6. doi: 10.1089/neu.2015.4071

52. Graham DP, Cardon AL. An update on substance use and treatment following traumatic brain injury. Addict Rev. (2008) 1141:148-62. doi: 10.1196/annals.1441.029

53. Ilie G, Mann RE, Hamilton H, Adlaf EM, Boak A, Asbridge M, et al. Substance use and related harms among adolescents with and without traumatic brain injury. J Head Trauma Rehabil. (2014) 1:101. doi: 10.1097/HTR.0000000000000101

54. Fishbein D, Dariotis JK, Ferguson PL, Pickelsimer EE. Relationships between traumatic brain injury and illicit drug use and their association with aggression in inmates. Int J Offender Therapy Comparative Criminol. (2016) 60:575-97. doi: 10.1177/0306624X14554778

55. Weil ZM, Karelina K, Corrigan JD. Does pediatric traumatic brain injury cause adult alcohol misuse: combining preclinical and epidemiological approaches. Exp Neurol. (2019) 317:284-90. doi: 10.1016/j.expneurol.2019.03.012

56. Weil ZM, Karelina K. Traumatic brain injuries during development: implications for alcohol abuse. Front Behav Neurosci. (2017) 11:135. doi: 10.3389/fnbeh.2017.00135
57. Corrigan JD, Hagemeyer AN, Weil Z, Sullivan L, Shi J, Bogner J, et al. Is pediatric traumatic brain injury associated with adult alcohol misuse? J Neurotrauma. (2020) 37:1637-44. doi: 10.1089/neu.2019.6897

58. Iverson KM, Hendricks AM, Kimerling R, Krengel M, Meterko M, Stolzmann $\mathrm{KL}$, et al. Psychiatric diagnoses and neurobehavioral symptom severity among OEF/OIF VA patients with deployment-related traumatic brain injury: a gender comparison. Womens Health Issues. (2011) 21:S210-217. doi: 10.1016/j.whi.2011.04.019

59. Grossbard J, Malte CA, Lapham G, Pagulayan K, Turner AP, Rubinsky AD, et al. Prevalence of alcohol misuse and follow-up care in a national sample of OEF/OIF VA patients with and without TBI. Psychiatric Services. (2017) 68:48-55. doi: 10.1176/appi.ps.201500290

60. Mayeux JP, Teng SX, Katz PS, Gilpin NW, Molina PE. Traumatic brain injury induces neuroinflammation and neuronal degeneration that is associated with escalated alcohol self-administration in rats. Behav Brain Res. (2015) 279:22-30. doi: 10.1016/j.bbr.2014.10.053

61. Weil ZM, Karelina K, Gaier KR, Corrigan TE, Corrigan JD. Juvenile traumatic brain injury increases alcohol consumption and reward in female mice. $J$ Neurotrauma. (2016) 33:895-903. doi: 10.1089/neu.2015.3953

62. Merkel SF, Razmpour R, Lutton EM, Tallarida CS, Heldt NA, Cannella LA, et al. Adolescent traumatic brain injury induces chronic mesolimbic neuroinflammation with concurrent enhancement in the rewarding effects of cocaine in mice during adulthood. J Neurotrauma. (2017) 34:165-81. doi: 10.1089/neu.2015.4275

63. Cannella LA, Andrews AM, Tran F, Razmpour R, Mcgary H, Collie C, et al. Experimental traumatic brain injury during adolescence enhances cocaine rewarding efficacy and dysregulates dopamine and neuroimmune systems in brain reward substrates. J Neurotrauma. (2020) 37:27-42. doi: 10.1089/neu.2019.6472

64. Nawarawong NN, Slaker M, Muelbl M, Shah AS, Chiariello R, Nelson LD, et al. Repeated blast model of mild traumatic brain injury alters oxycodone self-administration and drug seeking. Eur J Neurosci. (2019) 50:2101-12. doi: 10.1111/ejn.14281

65. Lowing JL, Susick LL, Caruso JP, Provenzano AM, Raghupathi R, Conti AC. Experimental traumatic brain injury alters ethanol consumption and sensitivity. J Neurotrauma. (2014) 31:1700-10. doi: 10.1089/neu.2013.3286

66. Weil ZM, Corrigan JD, Karelina K. Alcohol abuse after traumatic brain injury: experimental and clinical evidence. Neurosci Biobehav Rev. (2016) 62:89-99. doi: 10.1016/j.neubiorev.2016.01.005

Conflict of Interest: The authors declare that the research was conducted in the absence of any commercial or financial relationships that could be construed as a potential conflict of interest.

Copyright (C) 2020 Oliverio, Karelina and Weil. This is an open-access article distributed under the terms of the Creative Commons Attribution License (CC BY). The use, distribution or reproduction in other forums is permitted, provided the original author(s) and the copyright owner(s) are credited and that the original publication in this journal is cited, in accordance with accepted academic practice. No use, distribution or reproduction is permitted which does not comply with these terms. 